\title{
Octavio Paz, Julio Cortázar: dos centenarios
}

\author{
Octavio Paz, Julio Cortázar: \\ Two Centenaries
}

\author{
Juan Gustavo Cobo (Colombia) \\ Escritor \\ coborda@gmail.com
}

\begin{abstract}
Resumen
Este texto presenta un acercamiento a la trayectoria de vida de estos grandes en la literatura. Octavio Paz, de México, y Julio Cortazar, de Argentina son contemporáneos y su trayectoria tuvo corrientes similares, tales como el surrealismo, y gustos, como la pintura, a pesar de sus discrepancias políticas. Este texto abarca las diferentes obras, pequeños fragmentos de ellas y una descripción de sus afinidades, en un cierto paralelismo, al ubicarlos en un contexto similar en la literatura y en la vida latinoamericana.
\end{abstract}

Palabras clave: literatura latinoamericana, surrealismo, Octavio Paz, Julio Cortázar.

\begin{abstract}
This text presents an approach to the life of these magnificent authors. Octavio Paz from Mexico and Julio Cortazar from Argentina are contemporary writers who had similarities -such as surrealism as their favorite trend, and their love for painting - in spite of their political differences. This article shows some fragments of their work as well as a parallel of their resemblances, by locating them within a similar context in Latin American literature and reality.
\end{abstract}

Keywords: Latin American literature, surrealism, Octavio Paz, Julio Cortázar. 


\section{Octavio Paz, Julio Cortázar: dos centenarios}

\section{Octavio Paz, Julio Cortázar: \\ Two Centenaries}

Juan Gustavo Cobo (Colombia)

Escritor

coborda@gmail.com

Ambos nacieron en 1914. Uno en México, el otro en Bruselas, de padres argentinos, y muy pronto iría a la que sería su patria para siempre: Buenos Aires. Octavio Paz, el mexicano, vivió de cerca la historia de su país. Su padre, como su abuelo, fueron figuras públicas. Uno como patriarca liberal. el otro como caudillo zapatista. Pero ambos eligieron la literatura como destino. Cortázar, con el seudónimo de Julio Denis, publica en 1938, su libro de poemas Presencia. Si bien Paz se inicia como poeta en 1933 con Luna silvestre, es en 1937 y en España, más concretamente en Valencia, donde aparecerán Bajo tu clara sombra y otros poemas sobre España. O sea que podemos considerarlos, en dos (o tres) extremos del mundo miembros de una misma generación que ya poseía un rasgo singular: un cierto cosmopolitismo viajero que no por ello perdía sus raíces.

Sin embargo, en 1947, Cortázar escribe su Teoría del túnel (que solo será conocida y publicada en 1994), donde en un razonado ensayo analiza las características de la novela y sugiere cómo el futuro de ella debe darse a partir de una síntesis de existencialismo y surrealismo. Surrealismo, concepción del universo y no sistema verbal, que busca la restitución, el reencuentro con la inocencia. Profundizará y será fiel a estos propósitos cuando en la década de 1950 viaja a París y luego se instala allí de manera definitiva. 
En 1945, Octavio Paz ingresa en el servicio exterior mexicano. Uno de sus primeros destinos será París (más tarde Japón y la India), donde a través de figuras, como Benjamin Péret o Paul Éluard, estará cerca del grupo surrealista y su figura central: André Breton. Escribirá un poema, "Noche en claro", incluido en Salamandra (1962), donde revive su diálogo nocturno por las calles de París con Breton y Péret. Pero quizás el mejor fruto de su estadía en París sería preparar y ver publicado en México en 1949 su libro Libertad bajo palabra. Que Julio Cortázar reseñará en la revista SUR, de Buenos Aires (número 182, diciembre de 1949).

Sabe distinguir entre (las palabras) que se ordenan poéticamente y las que solo por prestigio retórico o psicológico tienden a instalarse en el poema; a estas últimas las arroja por la borda, o las neutraliza sometiéndolas a curiosas significaciones marginales, que son uno de los encantamientos de su verso (Obra crítica 2, p. 207).

Elemental y entrañable para hacerse comunicable, tal la opinión de Cortázar en su primera lectura de Octavio Paz.

\section{Surrealismo compartido}

En 1949, Julio Cortázar publicó una nota titulada "Un cadáver viviente". Comenzaba así: "Claro, me refiero al surrealismo". Y luego de demostrar en forma palmaria que no estaba tan muerto como se deseaba, concluía:

Conviene acordarse de que del primer juego surrealista con papelitos nació este verso: "El cadáver exquisito beberá el vino nuevo". Cuidado con este vivísimo muerto que viste hoy el más peligroso de los trajes, el de la falsa ausencia, y que presente como nunca, allí donde se lo sospecha, apoya sus manos enormes en el tiempo para no dejarlo irse sin él, que le da sentido. Cuidado, señores, al inclinaros sobre la fosa para decirle hipócritamente adiós, está detrás vuestro y su alegre, necesario empujón inesperado puede lanzaros dentro, a conocer de veras esta tierra que odíais a fuerza de ser finos, a fuerza de estar muertos en un mundo que ya no cuenta con vosotros (Obra crítica 2, Madrid, Alfaguara, 1994, pp. 179-180).

En 1954, Octavio Paz dictaba una conferencia en la Universidad Nacional de México que se titulaba "El surrealismo" y que compartía el mismo tono de Cortázar en su nota: 
Pero el cadáver estaba vivo. Tan vivo que ha saltado de su foso y se ha presentado de nuevo ante nosotros, con su misma cara terrible e inocente, cara de tormenta súbita, cara de incendio, cara y figura de hada en medio del bosque encantado. Seguir a esa muchacha que sonríe y delira, internarse con ella en las profundidades de la espesura verde y oro, en donde cada árbol es una columna viviente que canta es volver a la infancia. Seguir ese llamado es partir a la reconquista de los poderes infantiles. Esos poderes -más grandes quizás que los de nuestra ciencia orgullosa - viven intactos en cada uno de nosotros. Son imaginación y deseo (Octavio Paz, Las peras del olmo, Barcelona, Seix Barral, 1982, pp. 136-151).

La actividad poética como operación mágica y el triángulo clave de libertad, amor y poesía son otros de los principios cardinales que Paz señala. El humor y la imaginación hacen que el mundo ya no sea más un "horizonte de utensilios", sino un campo magnético. Donde el yo convertido en ilusión (hablar sería crear) nos acerca la convicción de que el amor es la forma más alta de la libertad: libre elección de la necesidad. Aventura interior donde nos descubrimos nosotros mismos.

III.

Los primeros cuentos de Julio Cortázar (Bruselas, 1914-París, 1984) aparecen fechados en 1937 y tratan temas que ya identificaríamos con su obra: vampiros, brujas, señoritas de provincia, que se aburren y sueñan. También fantasías de muerte y crímenes que parecen suceder en otro plano, en una imprevista forma de resolverse, con abuelas y familias ceñidas a estrictos horarios de comidas, noticieros y piyamas y pantuflas a una hora inalterable. Pero siempre ocurrirá algo no programado en esos escenarios que cambian de forma y orientación. Citemos dos fragmentos, uno de 1943 que refleja muy bien el tono y la atmósfera ya tan cortazariana:

La juventud de Paula ha sido triste y silenciosa, como ocurre en los pueblos a toda muchacha que prefiere la lectura a los paseos por la plaza, desdeña pretendientes regulares y se somete al espacio de una casa como suficiente dimensión de vida. Por eso, al apartar ahora los claros ojos del tejido - un pull-over gris simplísimo-, se acentúa en 
su rostro la sombría conformidad que alcanza la paz a través de moderado razonamiento y no con el alegre desorden de una existencia total. Es una muchacha triste, buena, sola. Tiene veinticinco años, terrores nocturnos, algo de melancolía. Toca Schumann en el piano y a veces Mendelssohn; no canta nunca pero su madre, muerta ya, recordaba antaño haberla oído silbar quedamente cuando tenía quince años, por la tarde (Bruja, p. 66, Julio Cortázar, Cuentos completos, vol. I, Buenos Aires, Alfaguara, 1999).

Ahora pasemos al propio Julio Cortázar, que también en 1943, en "Distante espejo" nos habla de la ciudad de Chivilcoy, en la provincia de Buenos Aires, donde se desempeña como profesor de la Escuela Normal y en horas libres lee la Biblia de Lutero, escucha jazz y mantiene un registro de sus pasiones intelectuales:

En 1939 fueron las obras completas de Sigmund Freud; en 1940 novelas inglesas y norteamericanas, poesía de Éluard y Saint-John Perse; 1941, Lewis Carroll (exhaustivamente), Kafka y unos libros indios de Fantone; en 1942, la historia de Grecia de Bury, las obras completas de
Thomas de Quincey y una tremenda bibliografía acerca de Sandro Botticelli (p. 82).

La provincia y la lectura, el magisterio y la aventura, tanto su personaje, Paula, como su autor, Cortázar, profesor, traductor, melómano, se nutren en aquellos años quietos. Ya que por debajo comienzan a insinuarse las relaciones inquietantes, las posesiones diabólicas, las máscaras que son rostros, los encuentros a deshora. Que muestran en climas anodinos y sofocantes las pulsiones sin nombre de esas estancadas cárceles que son los pueblos camuflados bajo las ceremonias rituales, detrás de las apariencias solo por fuera comunes. Ya arden las llamas de lo insólito y marginal, como sucederá cuando se instale en Buenos Aires y publique, en 1951, su primer libro de cuentos, Bestiario, a los que seguirán entre otros, Las armas secretas (1959) y Todos los fuegos el fuego (1966).

Se ha casado con Aurora Bernárdez, ella traduce a Faulkner y Sartre, él las Memorias de Adriano, de Marguerite Yourcenar, y ambos trabajan en la Unesco como traductores profesionales en insólitas conferencias por el mundo, que se enlazan con otras de la FAO o de la Comisión de Energía 
Atómica, con sede en Viena, que les permiten vivir y viajar por muchas partes. Entre otros lugares, a Nueva Delhi, donde Octavio Paz, embajador de México en la India, lo alojará en la residencia oficial.

Allí se incrementará, en textos y poemas, un diálogo que se había reiterado con la inclusión de un poema de Octavio Paz en Rayuela (1963) y de un elogioso ensayo de Cortázar sobre Libertad bajo palabra (1949). En la página 618 de Rayuela:

Mis pasos en esta calle

Resuenan

En otra calle

Donde oigo mis pasos

Pasar en esta calle

Donde

Solo es real la niebla

(Octavio Paz)

Por ello, mantendrá los versos de Octavio Paz como una clave que abre otras puertas, que convoca nuevos sentidos y aperturas a otros mundos. En la página 484 citará Cortázar a Octavio Paz: "muslos de sol, recintos del verano".

Pero también se da, vía Susuki, el budismo zen: desprendernos de nosotros, vernos alejarnos. Media la incurable nadería del yo "como si yo fuera alguien que me está mirando" (p. 461). Y a partir de Morelli, teórico que dentro de la novela reflexiona sobre ella, una muy amplia, erudita y exhaustiva meditación sobre el hecho de escribir. Donde el lector será copartícipe y copadeciente de la experiencia por la que pasa el novelista, "en el mismo momento y en la misma forma” (p. 453). Porque el lenguaje, ya petrificado en fórmulas, ya fosilizado en lugares comunes, necesita ser revivido, "del ser al verbo, no del verbo al ser". Lo que cuenta no es escribir. Es desescribir.

Por ello, es necesario considerar el lenguaje como el tema capital. La ruptura y demolición de lo que estaba congelado y que era necesario dinamitar. En los textos de Aguila o sol (1949-1950), Octavio Paz incluye una sección titulada "Trabajos del poeta”. Comparto el número XII, que muestra muy bien sus propósitos. Concentrados ataques a las mismas limitaciones que nos hemos impuesto. Obstáculos que por negligencia, desidia o dejadez complaciente nos impiden superar esa pasividad de quien apenas sí subsiste entre lugares comunes y fórmulas desgonzadas. Quizás al otro lado del muro encontremos la vida plena y no soportada o recortada. 
Luego de haber cortado todos los brazos que se tendían hacia mí; luego de haber tapiado todas las ventanas y puertas; luego de haber inundado con agua envenenada los fosos; luego de haber edificado mi casa en la roca de un No inaccesible a los halagos y al miedo; luego de haberme cortado la lengua y luego de haberla devorado; luego de haber arrojado puñados de silencio y monosílabos de desprecio a mis amores; luego de haber olvidado mi nombre y el nombre de mi lugar natal y el nombre de mi estirpe; luego de haberme juzgado y haberme sentenciado a perpetua espera y a soledad perpetua, oí contra las piedras de mi calabozo de silogismos la embestida húmeda, tierna, insistente, de la primavera.

Por su parte, en 1962, Julio Cortázar, en sus Historias de cronopios y de famas emplea otra arma peligrosa: el humor. Y lo hace contra el mayor enemigo posible: aquel que está dentro de nosotros y, poco a poco, nos encoge, arruga y hace desaparecer: el tiempo mismo. Que creemos usar y dominar y es él quien nos esclaviza como en este "Preámbulo a las instrucciones para dar cuerda al reloj":
Piensa en esto: cuando te regalan un reloj te regalan un pequeño infierno florido, una cadena de rosas, un calabozo de aire. No te dan solamente el reloj, que los cumplas muy felices y esperamos que te dure porque es de buena marca, suizo con áncora de rubíes; no te regalan solamente ese menudo picapedrero que te atarás a la muñeca y pasearás contigo. Te regalan —no lo saben, lo terrible es que no lo saben-, te regalan un nuevo pedazo frágil y precario de ti mismo, algo que es tuyo pero no es tu cuerpo, que hay que atar a tu cuerpo con su correa como un bracito desesperado colgándose de tu muñeca. Te regalan la necesidad de darle cuerda todos los días, la obligación de darle cuerda para que siga siendo un reloj; te regalan la obsesión de atender a la hora exacta en las vitrinas de las joyerías, en el anuncio por radio, en el servicio telefónico. Te regalan el miedo de perderlo, de que te lo roben, de que se te caiga al suelo y se rompa. Te regalan su marca, y la seguridad de que es una marca mejor que las otras, te regalan la tendencia a comparar tu reloj con los demás relojes. No te regalan un reloj, tú eres el regalado, a ti te ofrecen para el cumpleaños del reloj. 


\section{Octavio Paz y Julio Cortázar recuerdan al Che Guevara}

En 1967, desde Nueva Delhi, Octavio Pazle responde al poeta español León Felipe agradeciéndole una carta poema y lamentando un desencuentro en México. Mientras le escribe llega la noticia: la muerte del Che Guevara. Guevara

La muerte del Comandante también es ruptura

Su memoria

no un fin no es una cicatriz es una continuidad que se desgarra para continuarse

es la hendidura La poesía entre una palabra y otra y el espacio configuración del inacabamiento.

En la edición de su Obra poética (1935-1988), que Octavio Paz publica a fines de 1990, hay una nota aclaratoria que plantea una matización sobre esta figura, y acorde con el poema un desgarramiento que es continuidad, en un propósito de unidad de estas naciones. El sueño trunco de Bolívar.

Cortázar, en Todos los fuegos el fuego, de 1966, había incluido un cuento que rendía un homenaje al Che. $\mathrm{El}$ Che, que desembarca, con asma y entre pantanos, para internarse en la selva y luego ascender a la montaña en Cuba. Alguien que ya prevé el desastre que se avecina. "De los ochenta nos han matado por lo menos a cincuenta o sesenta”. Pero que también cambia el tono al recordar un cuarteto de Mozart, llamado La caza, al trasponer "una ceremonia salvaje a un claro goce pensativo", "una torpe guerra a un orden que le dé sentido". Conmovido por su muerta, Cortázar dedicará al Ché Guevara un poema fraterno.

\section{AL CHE}

Yo tuve un hermano.

No nos vimos nunca pero no importaba. Yo tuve un hermano que iba por los montes mientras yo dormía.

Lo quise a mi modo, le tomé su voz libre como el agua, caminé de a ratos cerca de su sombra.

No nos vimos nunca pero no importaba, mi hermano despierto mientras yo dormía, mi hermano mostrándome detrás de la noche su estrella elegida.

(Madrid, La Estafeta Literaria, núm. 383, 18 de noviembre de 1967).

Grandes traductores ambos, a Paz y a Cortázar los une también su pasión por la pintura. Escribieron 
sobre pintores amigos y llegaron a coincidir en textos complementarias sobre el pintor catalán Antoni Tàpies. Son tantos sus puntos en común y también, quizá, sus discrepancias políticas que hoy, al celebrar su doble centenario de nacimiento, lo mejor es señalar estas primeras afinidades $\mathrm{y}$ volver a leerlos y releerlos porque ellos dos juntos cambiaron la literatura latinoamericana en un momento clave de su historia.

\section{Bibliografía sobre Julio Cortázar}

Bernárdez, A. y Álvares Garriga, C. (editores) (2014). Cortázar de la A a la Z. Álbum biográfico. Bogotá, Alfaguara.

García Canclini, N. (1968). Cortázar una antropología poética. Buenos Aires: Nova.

Goloboff, M. (1998). Julio Cortázar. La biografía. Bogotá: Seix Barral.

Lastra, P(editor). (1981). Julio Cortázar. Madrid: Taurus.

Lezama Lima, J. y Vargas Llosa, M. etal. Cinco miradas sobre Cortázar Buenos Aires: Tiempo Contemporáneo.

Peri Rossi, C. (2001). Julio Cortázar, Barcelona: Omega.
Sola, G. (1968). Julio Cortázar y el hombre nuevo. Buenos Aires: Suramericana.

Yurkievich, S. (1987). Julio Cortázar, al calor de tu sombra. Buenos Aires: Legasa.

\section{Bibliografía sobre Octavio Paz}

Ruy Sánchez, Aberto .Una introducción a Octavio Paz. México, Breviarios 579, Fondo de Cultura Económica, 2013.

Phillips, Rachel. Las estaciones poéticas de Octavio Paz México, Breviarios 257, Fondo de Cultura Económica, 1976.

Xirau, Ramón .Octavio Paz: el sentido de la palabra. México, Joaquín Mortiz, 1970.

Poniatowska, Elena . Octavio Paz. Las palabras del árbol. México, Plaza y Janés, 1998.

Schärer-Nussberger, Maya .Octavio Paz. Trayectorias y visiones. México, Fondo de Cultura Económica, 1989.

Gianferrer, Pere . Lecturas de Octavio Paz Barcelona, Anagrama, 1980.

Octavio Paz. Volumen colectivo editado por Pere Gimferrer. Madrid, Taurus, 1982. Incluye el texto de Julio Cortázar : "Homenaje a una estrella de mar". 